\title{
Oposições dialéticas do phármakon no Fedro de Platão
}

\author{
FÁBIO FORTES \\ Universidade Federal de Juiz de Fora (UFJF)
}

DOI: $10.36446 /$ rlf2020169

Resumo: Tendo como ponto de partida a ambiguidade contida na metáfora do phármakon associada à escrita no Fedro de Platão, neste artigo pretendemos examinar os demais contextos em que essa palavra aparece nesse diálogo. Nosso objetivo é compreender o emprego da metáfora farmacológica para a determinação da escrita, e do modo como as diferentes oposições que ela engendra colaboram para compreender o movimento dialético. Por meio da explicação dessas contraposições, pretendemos mostrar que as palavras escritas em Platão estão permanentemente sujeitas a um renversement de sentidos, e que o fruto dessas disassociações e congruências constitui exemplificação da própria dialética. Para isso, consideramos também a leitura que Derrida (2004) faz da passagem, mas a transcendemos na medida em que, ao considerarmos as diferentes oposições dialéticas contidas no diálogo, não vislumbrarmos, como efeito do phármakon platônico, uma centralidade da escrita (ou da oralidade) para Platão. 
Palavras-chave: escrita, phármakon, dialética.

\title{
Dialectical oppositions of pharmakon in Plato's Phaedrus
}

\begin{abstract}
Taking as the starting point the ambiguity contained in the pharmakon metaphor associated with writing in Plato's Phaedrus, in this article we intend to examine the contexts in which this word appears in this dialogue. Our goal is to understand the use of the pharmacological metaphor for the determination of writing, and how the different oppositions that it engenders collaborate to understand the dialectical movement itself. By means of explaining these oppositions, we intend to show how the written words in Plato are permanently subject to a renversement of meanings, and that the fruit of these disassociations and congruences is the very exemplification of dialectics itself. For this, we also consider Derrida's (2004) reading of the passage, but we transcend it in that, when we consider the different dialectical oppositions contained in the dialogue, we do not recognise any centrality given to writing (or to orality) as an effect of the Platonic pharmakon.
\end{abstract}

Key-words: writing, pharmakon, dialectics.

\section{Introdução}

Tas últimas décadas, muita tinta tem sido empregada em inter1 pretações da palavra phármakon no Fedro de Platão, vocábulo associado à escrita na famosa passagem que contém o "Mito de Theuth" (274b-278b). ${ }^{1}$ A mais famosa dessas interpretações talvez seja a de Derrida

\footnotetext{
${ }^{1}$ Lendo a famosa "crítica à escrita” com Krämmer 1990, Szlezák 2009, 2011; Reale 2004, 2007; Perine 2014, e outros importantes representantes da chamada "Escola de Tübingen-Milão", devemos considerar a escrita em uma posição secundária, em prol de uma releitura da filosofia de Platão à luz de princípios não escritos, as chamadas "doutrinas não escri-

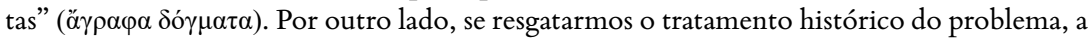
partir de Schleiermacher 2008, e chegarmos a posições mais contemporâneas, tais como as de Vlastos 1981, Brisson 2003, Dixsaut 2001 e Trabattoni 1994, 2003, não somente poderemos oferecer uma interpretação que, em ampla medida, reabilita a importância do texto escrito para a leitura de Platão, como oferece também um tratamento do problema da linguagem alternativo à resolução estritamente histórica da questão. Outras referências relevantes do “estado da arte da discussão”, conferir Reis 2014; Szlezák 2009; Trabattoni 1994, 2003.
} 
(2004), em cujo ensaio se analisa, à luz do Fedro, as implicações da ambiguidade contida nessa metáfora não somente para a compreensão do diálogo em questão, mas (talvez) também de toda a obra platônica.

Se a análise derridiana parece ter o mérito de não reduzir a crítica à escrita contida na passagem a uma disputa entre a admissão ou inadmissão dessa arte na pesquisa filosófica, e de considerar a estrutural ambiguidade com que a questão é formulada por Platão; por outro lado, o compromisso com os postulados de uma leitura pós-moderna deixa à sombra oposições no âmbito do próprio diálogo que ainda se nos afiguram incontornáveis, tais como as separações realizadas no campo do lógos (retórico e dialético), que abarcam outras distinções fundamentais para a compreensão da passagem: reminiscência $v s$. recordação, conhecimento interno (ligado à $p s y k h \underline{e}) v s$. conhecimento externo (ligado às impressões, aos týpoi da escritura) entre outras.

Assim, tendo como ponto de partida a ambiguidade contida na metáfora do phármakon associada à escrita no Fedro, neste artigo pretendemos examinar quais são os contextos em que essa palavra aparece nesse diálogo, com vistas a compreendermos a sua associação à escrita, na passagem específica do "Mito de Theuth", considerando também as oposições fundamentais do pensamento filosófico de Platão que emergem no diálogo, oposições que representam, em suma, uma operação dialética, e que têm lugar de destaque no Fedro. ${ }^{2}$ Particularmente, pretendemos mostrar, à luz desse diálogo, como as palavras escritas em Platão estão permanentemente sujeitas a um renversement de sentidos, sendo que o fruto dessas disassociações e congruências constitui exemplificação da própria dialética. Para isso, consideramos não somente a passagem em que a metáfora do phármakon aparece associada à escrita, como também todas as demais ocorrências do termo ao longo do diálogo, o que nos impõe, portanto, uma leitura mais global do Fedro.

${ }^{2}$ Não é possível pressupor um conceito unívoco e estável de dialética em Platão, considerando, sobretudo, como nos ensina Dixsaut 2001, que se trata, antes, de um conceito em permanente "metamorfose", adequado à natureza do objeto e de cada contexto investigativo. De forma ampla, contudo, poderíamos tomar como "dialética" o conjunto das reflexões que, centradas na análise do $\lambda o ́ \gamma o \varsigma$, de diferentes maneiras (divisão, separação, utilização de mitos etc.), busca encontrar uma metodologia de pesquisa de diferentes objetos. No caso particular deste artigo, consideramos dialética tal como ela é definida no próprio Fedro (265e1-266c5; 249b6-c1), como o procedimento de divisão (diaíresis) e reunião (synagogé), que se realiza também no âmbito da linguagem embora também a noção de dialética como simples contraposição, diferenciação estejam igualmente presentes no Fedro (Santa Cruz, 1992; Fortes, 2019). 


\section{O ambíguo estatuto do lógos}

Fedro: Que te parece o discurso, Sócrates? Não é extraordinária a maneira de se expressar, entre outras coisas, pelo vocabulário? Sócrates: É divina, por certo, meu amigo, a ponto de estar estupefato, Fedro, e passei por isso por tua causa, com os olhos em ti, que a mim parecias resplandecente à medida que lias o discurso. Convencido de que entendes disso bem mais do que eu, segui-te, e ao seguir, acompanhei-te neste delírio báquico, ó divina cabeça.

Fedro: Ora! Parece então ser o caso de brincar desse modo?

Sócrates: Pareço brincar e não falar sério? (Phdr. 234c6-d8) $)^{3}$

excerto citado em epígrafe, que introduz o chamado "primeiro
interlúdio" do Fedro (234c6-237a8), enseja talvez uma das mais 220 I irônicas passagens de todo o diálogo. Fedro anseia pela aprovação de Sócrates quanto à avaliação que faz do discurso de Lísias, cuja apresentação Fedro qualifica como "extraordinária" (ن่ $\varepsilon \rho \varphi v \tilde{\omega} \varsigma)$, sobretudo pela sua elaboração em palavras ( $\tau$ oĩ ỏvó $\mu \alpha \sigma \imath v$ ). A réplica de Sócrates não somente parece assentir com o interlocutor, mas também alçar o seu discurso a um patamar

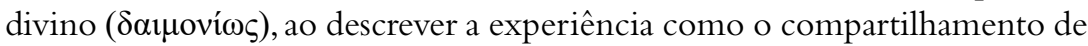
um êxtase báquico ( $\sigma v v \varepsilon \beta \alpha ́ \kappa \chi \varepsilon v \sigma \alpha)$. Não passa despercebida a ironia contida nessas palavras; tanto é assim, que Fedro não se furta a apresentar seu protesto contra tom debochado do amigo, que mais parece brincar ( $\pi \alpha i \zeta \varepsilon \imath v)$ do que

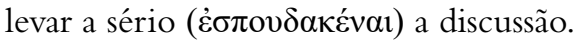

A ironia presente nos comentários de Sócrates, associada ao fato de eles ora elogiarem, ora tecerem críticas ao discurso lisiânico, ao lado da escolha vocabular empregada por Platão, permitem-nos destacar certa ambiguidade que caracteriza a passagem. Além disso, Sócrates não responde à indignação de seu amigo senão interrogativamente (234d8) - afinal, estaria ele levando a sério ou simplesmente gracejando com seus comentários?

\footnotetext{
${ }^{3}$ Utilizamos neste artigo a tradução de Maria Cecília Gomes dos Reis 2016. Foi também cotejada a tradução de Souza e Santos 2016. Seguimos o texto grego editado por Burnet 1910 cotejado com a edição de H. Yunis 2014.
} 
Quando se dirige a Sócrates, Fedro destaca o caráter extraordinário

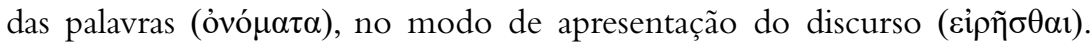
Essa alusão discreta à expressão linguística, em que se inclui a seleção vocabular, parece ser a senha com que Platão chama atenção do leitor para um exame mais atento das palavras que se seguem, do modo como elas próprias são escolhidas e empregadas na sequência da réplica de Sócrates e que tipo de sentidos elas evocam.

Com efeito, ao descrever sua experiência de ouvinte do discurso proferido por Fedro, Sócrates vale-se de palavras e expressões que dão margem a interpretações divergentes: afirma "estar divinamente ( $\delta \alpha \mu$ oví $\omega \varsigma)$ estupefato

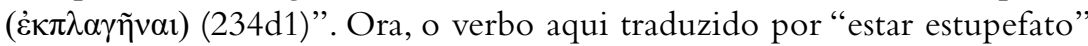
não necessariamente possui um matiz semântico elogioso, antes se refere a uma espécie de arrebatamento dos sentidos - seja pela admiração, seja pelo medo, seja pelo terror. ${ }^{4}$ Do mesmo modo, o advérbio empregado

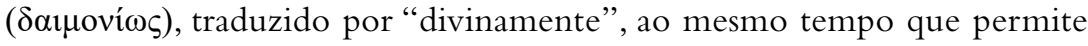
ser associado ao caráter superior, maravilhoso, extraordinário da divindade

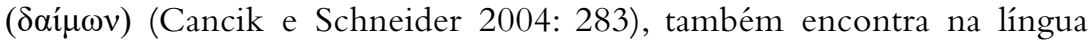
grega acepções negativas, denotando expressão de desdém, compaixão, ironia ou má sorte. O mesmo ocorre com o verbo com o qual Sócrates qualifica sua experiência: "compartilhar de um delírio báquico" (234d5:

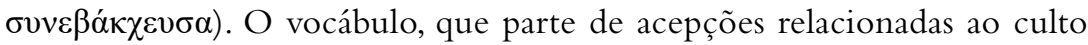
do deus Dioniso (Cancik e Schneider 2004: 498), também permite ser compreendido como "agir desmedidamente", como que "tomado por um frenesi", "descontrolado".

Assim, a réplica de Sócrates, que corresponde ao primeiro momento de reflexão sobre o lógos no Fedro, insinua uma crítica à linguagem que se apresenta de forma ambígua, a partir do emprego das próprias palavras com que ela é formulada nos comentários de Sócrates. Afinal, poderíamos considerar a posição socrática claramente contrária ou a favor daquela primeira opinião de Fedro, que considerava a expressão linguística do discurso de Lísias "extraordinária" (نं $\varepsilon \rho \varphi v \tilde{\omega} \varsigma)$ ?

Sem pretensão de oferecermos uma resposta para essa questão, queremos apenas apontar, de antemão, que essa passagem é bastante ilustrativa do modo como a crítica ao lógos, em geral, e à escrita, em particular, desenvol-

\footnotetext{
${ }^{4}$ Conforme indica Bailly 2000, o verbo ekplésso ou ekplétto, tem como acepções possíveis as de "ser derrubado por um golpe"; "estar atordoado, admirado, tomado de medo". De acordo com o verbete de LSJ destacamos, entre os sentidos dessa palavra: "perder os sentidos por um choque, surpresa ou pânico"; "ser dominado por uma paixão dominante e repentina".
} 
ve-se ao longo desse diálogo. ${ }^{5}$ Diferente do que se passa com outros temas filosóficos que são discutidos por Platão a partir de uma tradição até certo ponto consagrada, cujas teses e princípios são debatidos e eventualmente corroborados ou refutados dialeticamente, a questão da linguagem (e da escrita, particularmente) limita-se a ser formulada como uma interrogação, e emerge sob o signo de uma dúvida, para a qual a ironia é um dos recursos estilísticos platônicos bastante adequados. ${ }^{6}$

Outra passagem do Fedro que demonstra a formulação aberta e dúbia do tema da linguagem no Fedro é aquela em que assoma, pela primeira vez, a reflexão sobre um dos gêneros da linguagem escrita praticados em Atenas, a logografia. No terceiro interlúdio do diálogo (257b7-259d9), ${ }^{7}$ o ponto é tratado por meio do confronto de opiniões que Fedro e Sócrates exibem quanto à arte dos logógrafos. ${ }^{8}$ Fedro traz à tona a opinião comum que considerava desonrosa a posição desses profissionais, cuja atividade, trazendo vergonha aos homens influentes e veneráveis da cidade (257d5-6), ainda os poderia associar à vergonhosa figura dos sofistas $(257 \mathrm{~d} 7-8)$. Sócrates intenta desfazer esse pré-julgamento considerando que: 1 . até os mais presunçosos dos políticos valorizam a logografia, que se revela um instrumento pelo qual eles podem enaltecer seus admiradores e, por conseguinte, a si próprios (257d9-258b5); 2. a escrita confere imortalidade aos oradores e aos políticos 222 I poderosos (tais como a Licurgo, Sólon ou Dario), aos quais se imputa, por causa das letras, semelhança com os deuses (258b10-c6).

Nesse sentido, nessa parte do diálogo, Sócrates parece desenvolver o seu raciocínio na direção de uma aparente absolvição in dubio pro reo da

${ }^{5}$ Conforme foi-nos indicado por um dos pareceristas anônimos deste artigo, a quem prestamos nosso devido agradecimento, poderíamos ainda acrescentar à análise um comentário sobre a passagem $242 \mathrm{e} 1$, onde verifica-se o emprego do termo katapharmakeúthentos, e que, de igual modo, poderia sugerir análoga ambiguidade no seu tratamento dado por Sócrates. Por razões que escapam a este texto, não nos foi possível aprofundar essa análise para apresentá-la também aqui.

${ }^{6}$ Além da passagem do Fedro aqui examinada, essa característica ambígua com que o tema da linguagem é tratado fica patente também no Crátilo, texto que, após demorada apresentação das possibilidades da prática da etimologia (396d-421c), encerra com uma afirmação bastante ambígua de Sócrates, no seu epílogo: "Pois é, talvez, Crátilo, seja dessa forma, talvez não" (Crátilo, 440d2-3).

${ }^{7}$ Seguimos aqui a sugestão de divisão do diálogo proposta por Reis 2016. A passagem citada trata-se de um interlúdio porque corresponde à transição entre a palinódia socrática e a discussão posterior sobre retórica. Nesse interlúdio os dialogantes discutem e formulam o novo problema de que vão tratar na sequência.

${ }^{8}$ Sobre o lugar dos logógrafos na cultura ateniense, conferir Centrone 2014: XIX; Cancik e Schneider 2004: 792; Yunis 2014: 170.

FÁBIO FORTES - Oposições dialéticas do phármakon no Fedro de Platão I 217-232 
escrita de discursos, ou, ao menos, no sentido de atenuar uma talvez mais incisiva crítica à escrita a ser apresentada adiante. De fato, como ele argumenta, não seria vergonhoso em si mesmo escrever discursos (258d1-2: oủ

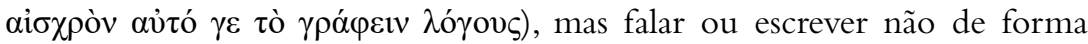

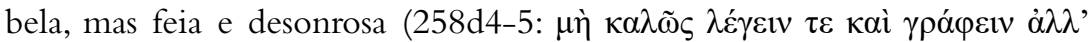

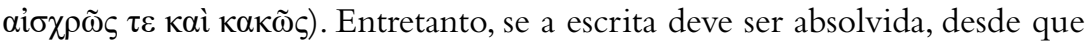
acompanhada de beleza, restaria ainda compreender, precisamente, em que consistiria a "bela escrita", isto é, "qual seria a maneira bela e não bela de escrever?" (258d7).

Essa questão de fundo, que parece motivar a reflexão sobre a logografia nessa passagem, volta à tona na reflexão sobre a invenção da escrita (274b-278b) e ilustra esse caráter ambíguo com que o problema é formulado em Platão. O problema da linguagem, do lógos - do escrever ( $\gamma \rho \alpha \varphi \varepsilon i v v)$, em particular - suscita uma indagação: seria a escrita amiga, inimiga ou indiferente à prática da filosofia, prática que, afinal, interessa de perto a Sócrates e que se cumpre determinar como dialética? Qual seria o modo do "escrever

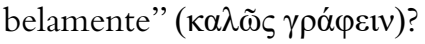

\section{As oposições fundamentais no embate sobre a escrita}

o item anterior, aludimos ao caráter ambíguo com que o pro-
blema da linguagem - e da escrita, em particular - é formulado no Fedro. A questão da escrita, tal qual apresentada no embate entre seu inventor Theuth e o rei Thamos contribui particularmente para agravar o grau de incerteza com que Platão apresenta o problema, a começar pelo termo pelo qual o inventor qualifica sua arte: um phármakon para a me-

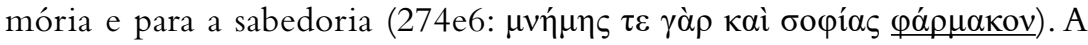
metáfora não era nova na tradição grega, como, por exemplo, já observamos em Ésquilo, Prom. 460-461, onde já se afirmava: “combinações de letras, memória de todas as coisas, artífice-mãe das Musas" (cf. $\gamma \rho \alpha \mu \mu \alpha ́ \tau \omega v$

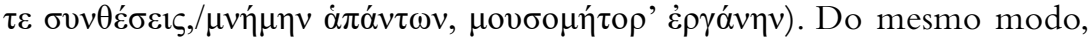
atribuindo a escrita a Palamedes, observa-se também a associação entre letra e memória em Eurípedes (TrGF 578: 1): "Inventei para a humanidade as letras - o remédio para o esquecimento -, somente dispondo correta-

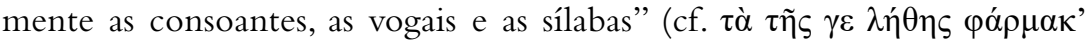

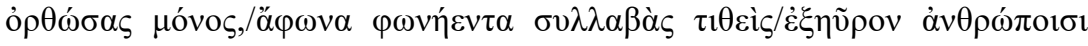
$\left.\gamma \rho \alpha ́ \mu \mu \alpha \tau^{\prime}\right)$.

Além disso, a polissemia desse termo em grego antigo é bem conhecida: em seu sentido mais usual - "remédio", "droga" - tal vocábulo pode 
ser, por exemplo, percebido em muitas partes do corpus Platonicum, ${ }^{9}$ mas nele também coexiste assumindo conotações discrepantes: "poção", "veneno". ${ }^{10} \mathrm{O}$ termo é empregado quatro vezes no Fedro (230d6, 270b6, 274e6, 275a5) e, na alquimia das palavras de Platão, o seu emprego nesse diálogo tem como efeito tornar a questão ainda mais complexa, requisitando-nos atitude interpretativa que enfrente o texto platônico como um constante desafio para o leitor, que

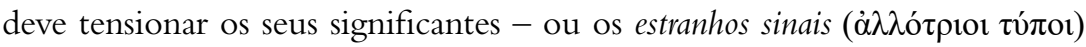
da escrita. Nesse sentido, muita tinta tem sido empregada em interpretações dessa palavra no Fedro; a mais famosa delas, talvez, seja a de Derrida 2004.

Segundo o filósofo franco-argelino, qualquer tentativa hermenêutica que consista em desfazer a ambiguidade presente no signo - incluindo até mesmo a sua tradução - já seria, em si, uma derrogação da filosofia de Platão, em prol de um "platonismo" (Derrida 2004: 297). Para Derrida, seria preciso, portanto, ler o Fedro na composição dessas duas forças ínsitas à palavra: não há remédio inofensivo; participando da doença e da cura, a escrita é parte do bem e do mal, do agradável e do desagradável (Derrida 2004: 299). Nesse sentido, o phármakon seria, no sentido derridiano, a condição para compreensão da diferença, ainda que ele próprio escape a qualquer lógica ou discurso, e nos aprisione dentro de seu sistema, sendo simultaneamente benéfico e maléfico.

Por essa razão, o exercício de captura de sentidos a partir da leitura de Platão não pode presumir a compreensão de um sistema definitivo, visto que o texto opera apenas na revelação de uma aparição, de um espectro (fantôme) (Derrida 2004: 305). Ler Platão, portanto, segundo Derrida, seria sempre o exercício de nos depararmos com a aporia - e nela nos determos.

Se a análise derridiana parece ter o mérito de não reduzir a crítica à escrita contida na passagem a uma disputa entre a admissão ou inadmissão dessa arte na pesquisa filosófica, e de considerar, como vimos, a estrutural ambiguidade com que a questão é formulada; por outro lado, o compromisso com os postulados de uma leitura pós-moderna deixa à sombra oposições que, malgrado todo o esforço de desconstrução, ${ }^{11}$ ainda se nos afiguram incontornáveis: as separações realizadas no campo do lógos (retórico e dialético), que abarcam outras distinções fundamentais para a compreensão da passagem: memória vs. recordação, conhecimento interno (ligado à psykhế) vs. conhecimento externo (ligado às impressões, aos týpoi da escritura).

\footnotetext{
${ }^{9} \mathrm{Na}$ República (3.406d1-3) e também no Górgias (467c7-10).

${ }^{10}$ No sentido de "veneno" a palavra vem empregada duas vezes no Fédon, associado à cicuta tomada por Sócrates. Em 57a1-3 e em 115a7-8.

${ }^{11}$ Sobre leituras “pós-modernas” de Platão, conferir Zuckert 1996.
} 
Ainda que venhamos a concordar com Derrida com o fato de que as linhas que demarcam fronteiras entre sofística e filosofia não sejam tão definidas - a ponto de, em muitos momentos, o filósofo e o sofista trocarem de posição (Derrida 2004:311) - e que sustentar uma contraposição forte entre a escrita sofistica e a escrita platônica seria, de certo modo, corroborar um platonismo à la Hegel (Zuckert 1996: 202) - não nos parece possível desconstruir todas as distinções que se nos afiguram efetivamente platônicas em prol de combater o "platonismo" - a menos que tal operação represente, como o próprio Derrida propõe, "um pequeno exercício" que subverta completamente a ordem do comentário (Derrida 2004: 305), o qual, entretanto, não é aqui o nosso caso. Assim sendo, além do "fim de linha" que a chave de leitura pós-moderna derridiana de Platão nos sugere (Zuckert 1996: 208), ainda nos interessa, efetivamente, compreender questões que lhe escapam: por que Platão, afinal, escolhe o vocábulo phármakon para caracterizar a escrita? Se a ambiguidade medicamento/veneno permanece latente, o que ela cura e o que envenena e qual sua relação com a memória?

A relação entre conhecimento, linguagem, doença e cura que, em última análise, justifica e, em certa medida, explica a metáfora farmacológica que se estende no Fedro manifesta-se ao longo de todo o diálogo. Ao se encontrar com Fedro, Sócrates afirma ser um "doente por ouvir discursos"

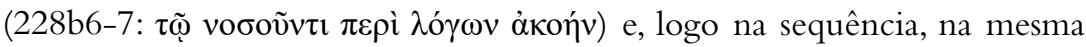

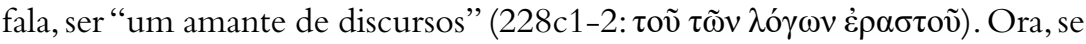
o "amante" por discursos é o mesmo que se disse "doente" por eles, a aproximação das duas expressões, nesse mesmo contexto dialógico, convida-nos a estabelecer um paralelo entre universo da "doença" (vóбos) e o do "amante"

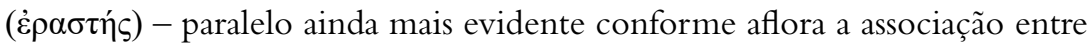
éros e doença que sustenta as teses dos discursos na sequência proferidos por Fedro e Sócrates (Phdr. 236a8-b2).

Nesse sentido, se é correto apontar que o tratamento conferido a éros e lógos no Fedro possa ser entendido como a demonstração do procedimento

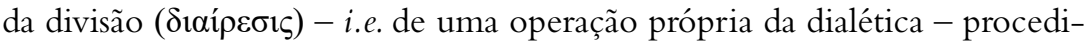
mento com o qual Platão teria, por meio dos discursos de Sócrates e Fedro, logrado estabelecer uma espécie de fissura nesses dois campos e nos permitido reconhecer uma demarcação, por assim dizer, entre gêneros distintos (um lógos e um éros efusivos, arrebatadores e irracionais versus um éros e um lógos, equilibrados, racionais, divinos e dialéticos), poderíamos aqui talvez estender essa divisão à noção de doença - e, por conseguinte, cura - ambas relacionadas ao lógos? Seria possível concluir que haveria também dois gêneros de doença, a requisitarem, cada um a seu modo, um gênero de phármakon apropriado? Se este é o caso, a noção de "doença", que evoca sentidos, a 
priori, francamente negativos; quando ligada ao lógos, entretanto, teria sofrido um completo renversement.

Um indício textual que pesa a favor dessa interpretação também se pode encontrar no mesmo contexto. Não nos parece ligeira a observação de Sócrates ao se declarar como um "companheiro coribântico" (228b7:

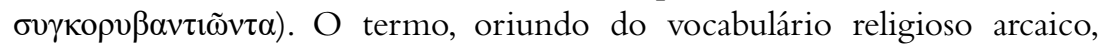
evoca, em uma conotação mais imediata, aqueles que se associam ( $\sigma 0 v-)$ aos rituais dos Coribantes (Kopú $\beta \alpha v \tau \varepsilon \varsigma$ ), que era o nome dado aos sacerdotes de origem frígio-cretense ligados à deusa Cibele e cuja performance ritual consistia em longas sessões de delírio e frenesi. ${ }^{12}$ Metaforicamente, Sócrates parece querer aludir ao estado extático (um enthousiasmós) em que se vê envolvido quando ouve discursos, o que, conforme comenta Yunis (2014: 89), antecipa a relação estabelecida entre éros e lógos, que se manifesta, conforme vimos, em sentidos opostos no primeiro discurso de Sócrates (237a-241d) e na palinódia (243e-257b). Assim, a alusão aos ritos extáticos associados aos Coribantes evocaria, a um tempo, tanto o êxtase irracional dos que se veem iludidos pela pretensa aparência de sabedoria dos discursos retóricos - com efeito, como apontamos antes, Sócrates viria a qualificar a experiência de

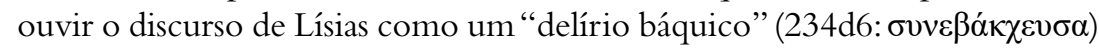
- quanto pela singular experiência de experimentar um delírio, possuído por um deus ( $\dot{\varepsilon} v \theta$ ovøiá $\zeta \omega v)$, quando se é sujeito da contemplação das coisas em si, franqueada mediante o exercício filosófico (249c5-d1).

Nesse sentido, compreende-se a filosofia não somente como éros, mas também como delírio e iniciação extática; aquilo que poderia, de outro modo, ser concebido como uma doença - um irracional e descontrolado domínio da psykhé - passa, justamente, a ser compreendido também como a possibilidade de sua libertação (249d4-7). As palavras em Platão, portanto, novamente são sujeitas a um renversement de sentidos, e o fruto dessas disassociações e congruências constitui exemplificação da dialética. Se a doença

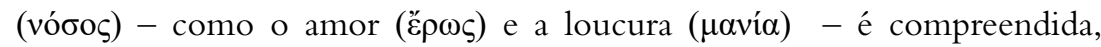
portanto, nas tensões que emergem do diálogo - no jogo de associações e distinções tecidas na malha do lógos de Platão - por que não o seria assim também com a escrita, que é, afinal, parte do lógos? Se essa análise estiver correta, então a ambígua valência dos sentidos de phármakon parece-nos bastante apropriada para referir-se metaforicamente à arte das letras.Vejamos.

${ }^{12}$ As fontes antigas ligadas aos coribantes podem ser conferidas em Eurípedes (Bacch. 121; Hipp. 143) e, sobretudo, em Platão (além dessa passagem do Fedro, também se entram menções em: Cri. 54d2-5, Smp. 215c5-6, Euthd. 272d4-e2, Lg. VII, 790c5-791b1). Para referências modernas, conferir Linforth 1946. 


\section{As oposições dialéticas e os diferentes efeitos do phármakon}

A primeira ocorrência do termo phármakon no texto (230d6),

$\mathrm{A}_{\mathrm{j} a ́ \text { associado ao discurso, aparece no âmbito de uma inusitada }}$ imagem: Sócrates alega que a promessa de ouvir o discurso de Lísias é o phármakon que o leva a sair de Atenas, em companhia de Fedro. O phármakon impele Sócrates a avançar, como a visão de um alimento, quando oferecido à frente de um animal, incita-o a se movimentar, uma imagem que vale a pena ser destacada:

Tu, no entanto, pareces ter descoberto a droga ( pegar a estrada. E, tal como quem quer tocar em frente um animal faminto e por isso aproxima dele um galho de fruta ou legume, também tu estendes para mim discursos em manuscritos, e assim pareces que podes me levar por toda a Ática, aonde quiseres (Phdr. 230d5-e1).

A imagem que a passagem acima descreve parece associar, inicialmente, o phármakon dos escritos (230d8: غ̇v $\beta 1 \beta \lambda i ́ o r \varsigma)$ ao apelo estritamente sensorial - à visão, ao olfato, ao paladar: sentidos que mobilizam o animal a ir em busca do alimento que vislumbra alcançar -, apelo, portanto, externo a qualquer racionalidade (o alimento continua a se mover, enquanto o animal também avança): trata-se de uma experiência psicagógica que, entretanto, não o leva a lugar algum. Enquanto se rende aos sentidos aguçados pela proximidade do alimento, o movimento do animal, relativamente ao seu objeto de desejo, é nulo: não diminui em um centímetro o espaço que se interpõe entre ele e o alvo do seu apetite.

Essa primeira imagem coaduna-se com a perspectiva de éros tal como assoma no discurso de Lísias/Fedro: "um desejo desprovido de

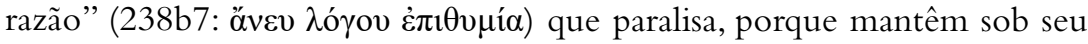

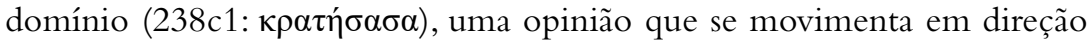

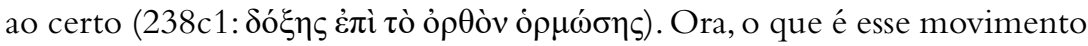
da opinião em direção ao certo, senão a própria filosofia? Mas a natureza do movimento filosófico é de uma ordem diversa do movimento que se realiza espacialmente - ou pelos discursos - não é o fato de o animal se pôr em curso que fará com que ele alcance seu alvo; não é o fato de Sócrates e Fedro terem saído da cidade ou ouvido os escritos de Lísias que ambos se reconciliarão com a filosofia. $\mathrm{O}$ movimento filosófico envolve um movimento anímico, um processo interno: a alma imortal é o motor gerador desse movimento (245c4-9) e o resultado desse movimento não é o deslocamento espacial, mas uma espécie de elevação, pelo pensamento, à altura dos deuses, ou aos inteligíveis, possibilitado mediante um processo ligado à memória: 
“[Os seguidores de Zeus, i.e. os filósofos] prosperam pela necessidade de pôr os olhos intensamente na direção do deus, inspirados e alcançando-os pela memória” (253a1-3). Nesse sentido, um éros que traduz o domínio do desejo

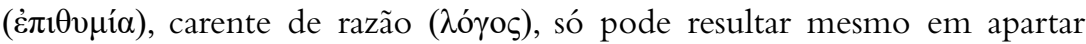
o amado da filosofia (239a8-b4) e, por outro lado, a filosofia consiste em atribuir ao lógos o papel de diretor do movimento anímico, para o qual a memória tem papel central.

Se a primeira aparição do phármakon no texto o associa, como vimos até aqui, a essa espécie de domínio sobre a alma, privando-a da razão e afastando-a da filosofia; se phármakon está associado às letras escritas (aos manuscritos que Fedro trazia consigo), poder-se-ia concluir, completando-se o silogismo, que a escrita afasta, portanto, a alma de seu caminho filosófico? Se nos limitarmos a essa passagem, seremos forçados a admitir que sim. Entretanto, como apontamos acima, Platão, ao longo do Fedro, desafia o leitor diante da polissemia dos significantes - e as ambiguidades que o signo linguístico possibilita são propícias a um renversement, como já testemunhamos na segunda passagem em que o termo ocorre no diálogo:

Sócrates: Há uma situação idêntica, suponho, da arte médica e justamente da retórica.

FEDro: Como assim?

Sócrates: Em ambas é preciso distinguir uma natureza - a do corpo, num caso, a da alma, no outro - se pretendes não apenas por destreza e experiência, mas pela arte, em um, produzir saúde e força ministrando remédios ( $\varphi \alpha ́ \rho \mu \alpha \kappa \alpha)$ e alimentação, e a outra, transmitir qualquer persuasão e virtude que se queira e virtude por meio de discurso e de práticas legais. (Phdr. 270b1-9)

A interpretação dessa passagem nos leva, se não a reverter, ao menos a colocar em suspensão a conclusão a que teríamos chegado a partir daquela primeira (230d5-e1). A relação entre doença e cura volta à tona no paralelo que Sócrates desenvolve entre a arte da medicina ( $\tau \varepsilon \dot{\chi} \chi \eta \eta$ i $\alpha \tau \iota \kappa \eta ́)$ e da retórica ( $\dot{\eta \tau о \rho ı к \eta ́) . ~ C o n s i d e r a n d o ~ q u e ~ e s t a ~ p r i m e i r a ~ a r t e ~ i n c i d a ~ s o b r e ~ c o r p o ~}$ (270b4: $\sigma \omega ́ \mu \alpha \tau o \varsigma)$ e a segunda sobre a alma (270b5: $\psi v \chi \tilde{\eta} \varsigma)$, Sócrates antecipa o tema da psicagogia, associada ao lógos, mas afirma, ligeiramente, aquilo que mais particularmente nos interessa neste momento: é necessário ser capaz de

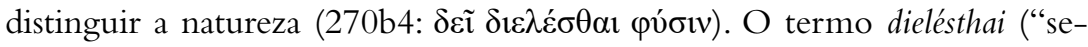
parar", "discernir", "dividir", "distinguir") remete-nos àquelas operações do lógos que, como Platão já apresentara, ensinam a "falar e a pensar" (266b4-5:

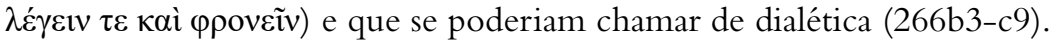

Ora, o que Platão nos sugere é a necessidade de submetermos as opiniões ao crivo desse processo dialético; nesse sentido, não basta nos li- 
mitarmos a avaliar um problema somente em uma direção, mas é condição fundamental apreender distinções (270c10-d8): a linguagem (a escrita, em particular) certamente não é um objeto simples, o que exige uma reavaliação, de modo a perceber as tensões inerentes a suas diferentes formas. Somente após esse exercício é que, então, teremos a oportunidade de nos posicionar com mais correção quanto aos possíveis benefícios ou malefícios que ela engendra.

Logo, essa atitude intelectual sugerida para o exame da questão uma abordagem dialética - implica assumir a complexidade do problema, do que decorre não podermos sustentar uma leitura redutora desse phármakon, quando se lhe aprecia apenas um de seus sentidos. A reflexão que essa passagem enseja, que se apresenta como antessala daquela em que Sócrates e Fedro realizam sobre a escrita ao longo da narrativa do Mito de Theuth, indica-nos, portanto, de que maneira interpretar as duas últimas ocorrências desse termo (274e6 e 275a5), já no cerne dessa narrativa.Vejamos como aparecem nas falas dos dois personagens do mito:

Mas quando chegou a vez da escrita, Theuth disse: "Esta é uma instrução, ó rei, que fará os egípcios mais sábios e de melhor memória. Pois foi descoberta

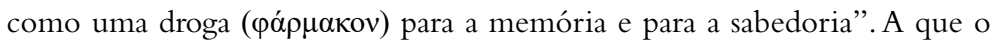
outro respondeu: "Engenhoso Theuth, um é aquele capaz de engendrar as artes, mas outro é o que julga qual o lote de dano e utilidade tratará a quem delas se servir. E tu, sendo o pai da escrita e por querer-lhe bem, dizes agora o contrário do poder que ela tem. Pois, por descuidar da memória, a escrita produzirá esquecimento nas almas dos que se instruírem, posto que, por uma persuasão exterior e pela ação de sinais estranhos, e não mais do interior de si e por si mesmos, recordarão. Portanto, descobriste uma droga ( não para a memória, mas para as recordações. (Phdr. 274e4-275a6)

É interessante observar que as letras $(\gamma \rho \alpha ́ \mu \mu \alpha \tau \alpha)$ são apresentadas por Theuth como uma "instrução" ( $\tau$ ò $\mu \alpha \dot{\theta} \theta \eta \mu \alpha)$. O substantivo neutro, que tem a raiz math-, também presente no verbo mantháno ("aprender", "instruir-se", "estudar") mostra uma concepção da escrita relacionada a uma faculdade que se aprende e, portanto, se ensina. Mediante essa instrução,

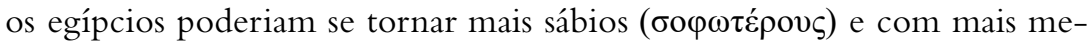

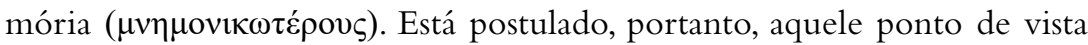
que examinamos no último item: que estabelece uma relação causal entre as letras - algo que se aprende - e a sabedoria. A réplica do rei reconhece nas letras o efeito contrário: ela é prejudicial à memória, porque leva os homens ao esquecimento em suas almas ( $\lambda \eta \dot{\eta} \theta \eta \nu \mu \grave{\varepsilon} v \dot{\varepsilon} v \psi v \chi \alpha \tilde{i} \varsigma)$, visto que o

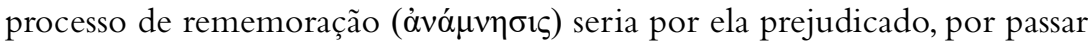


a se estabelecer mediante um evento externo ( $\varepsilon \xi \omega \theta \varepsilon v)$ e não interno à alma

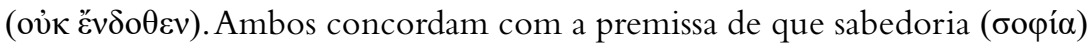
esteja ligada à memória $(\mu \nu \eta ́ \mu \eta)$. A divergência entre os dois reside no fato de que enquanto aquele sublinha o papel da escrita como phármakon que gera a sabedoria (auxiliando a memória), este lhe atribui o papel de phármakon que, em sentido contrário, causa esquecimento na alma dos aprendizes (por levar a um descuido com a memória). Enquanto para Theuth a escrita é aliada da memória; para Thamos, porém, é inimiga; para aquele, ela torna os seres mais sábios; para este pode somente prestar auxílio à re-

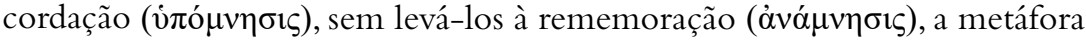
farmacológica, na qual está ínsita, conforme vimos, a ambiguidade (cura/ veneno), mostra-se, portanto, mais uma vez adequada à caracterização da linguagem escrita.

\section{Considerações finais}

To seu comentário ao Fedro de 1972, La pharmacie de Platon, De1 rrida defendeu a tese de que Platão, mediante a ambiguidade do phármakon, teria ensejado uma tentativa de sublinhar a superioridade da oralidade sobre a escrita, intento no qual, contudo, teria falhado, tornando a escrita, paradoxalmente, o centro da sua filosofia. Isso se daria porque a caracterização da escrita como um phármakon introduziria, desde o princípio, uma ambiguidade intrínseca: o encantamento que ela produz - ao mesmo tempo um "remédio" e um "veneno" - deixaria em aberto a possibilidade de engendrar consequências tanto benéficas quanto maléficas (Derrida 2004: 264). Além disso, para Derrida, o enquadramento da crítica à escrita no âmbito de uma narrativa mítica, colaboraria também para enfraquecê-la (Derrida 2004: 270).

Contudo, conforme apontamos nesse artigo, parece-nos razoável admitir, com Derrida, a incontornável ambiguidade do lógos (e, particularmente, da escrita) no Fedro de Platão, sendo a metáfora farmacológica um signo dessa ambiguidade, essa ambiguidade não nos permite concluir, tal como o filósofo argelino, seja pelo intuito de se sublinhar uma superioridade da oralidade sobre a escrita, seja tampouco pelo efeito inverso que o filósofo teria logrado. Com efeito, analisando as diferentes transformações da palavra phármakon no diálogo, em seus quatro contextos de ocorrência, bem como considerando as oposições dialéticas fundamentais que nele aparecem (entre esquecimento/memória; conhecimento externo/interno; sensível/inteligível, entre outras), nossa conclusão não pretende senão sublinhar novamente o caráter ambíguo do tema da escrita, que só pode, portanto, apontar 
em direções divergentes no pensamento de Platão: a escrita é o meio pelo qual tanto se possibilita, quanto se impede o acesso ao saber, tal qual o lógos, que tanto é matéria de um discurso meramente logográfico, quanto também é da dialética que é a condição para a filosofia. ${ }^{13}$

\section{REFERÊNCIAS}

Bailly, A. (2000), Le grand Bailly: Dictionnaire Grec-Français, edição e revisão de L. Séchan e P. Chantraine (Paris: Hachette).

Brisson, L. (2003), Leituras de Platão, tradução de S. M. Maciel (Porto Alegre: Edipucrs).

Cancik, H. e Schneider, H. (2004) (eds.), Brill's New Pauly Encyclopaedia of the Ancient World. V.1-5 (Leiden: Brill).

Centrone, B. (2014), "Introduzione", en Fedro, tradução italiana de P. Pucci, introdução e notas de B. Centrone (Roma: Laterza).

Derrida, J. (2004), "La pharmacie de Platon”, em Phèdre, tradução e apresentação de L. Brisson (Paris: GF Flammarion).

Dixsaut, M. (2001), Métamorphoses de la dialectique dans les dialogues de Platon (Paris:Vrin).

Fortes, F. (2019), A dialética e as letras: Imagens e paradigmas do pensar no Fedro de Platão. Tese de Doutorado. Programa de Pós-graduação em Filosofia (Belo Horizonte: Fafich-UFMG).

Krämer, H. J. (1990), Plato and the Foundations of Metaphysics: A work on the Theory of the Principles and Unwritten Doctrines of Plato with a Collection of the Fundamental Documents, edição e tradução inglesa da J. R. Catan (Albany: State University of New York Press).

Linforth, I. M. (1946), “The corybantic rites in Plato”, University of California Publications in Classical Philology, 13: 121-162.

Perine, M. (2014), Platão não estava doente (São Paulo: Loyola).

Platão, A República, tradução e notas de M. H. da Rocha Pereira (Lisboa: Fundação Calouste Gulbenkian, 2014, 14. ed.).

Platão, Fedro, edição bilíngue, tradução e apresentação J. Cavalcante de Souza, posfácio e notas de J.Trindade Santos (São Paulo: Editora 34, 2016).

Platão, Fedro, tradução, introdução e notas de M. C. Gomes dos Reis (São Paulo: Companhia das Letras, 2016).

${ }^{13}$ O presente trabalho foi realizado com apoio da Coordenação de Aperfeiçoamento de Pessoal de Nível Superior - Brasil (CAPES) - Código de financiamento 001 - durante meu estágio de pesquisa pós-doutoral no Département de Sciences de l'Antiquité, na Universidade de Liège, na Bélgica. É um desenvolvimento da tese de Doutorado defendida em agosto/2019 na Faculdade de Filosofia e Ciências Humanas (FAFICH) da UFMG. 
Platão, Phaedrus, editado por H.Yunis (Cambridge: Cambridge University Press, 2014).

Reale, G. (2004), Para uma nova interpretação de Platão, tradução de M. Perine (São Paulo: Loyola, $2^{\mathrm{a}}$ ed.).

Reale, G. (2007), Platão: História da Filosofia Grega e Romana, vol. III, tradução de H. C. de Lima Vaz e M. Perine (São Paulo: Loyola).

Reis, M. C. G. (2014), “O diálogo Fedro de Platão como metadialético”, Sala Preta, 14, (2): $72-84$.

Rossetti, L. (1992) (ed.), Understanding the Phaedrus: Proceedings of the II Symposium Platonicum (Sankt Augustin: Academia).

Santa Cruz, M. I. (1992), "Division et Dialectique dans le Phèdre”, en L. Rossetti (ed.), Understanding the Phaedrus: Proceedings of the II Symposium Platonicum (Sankt Augustin: Academia, 253-256).

Schleiermacher, F. (2008), Introdução aos diálogos de Platão, tradução de G. Otte, revisão e notas de F. Rey-Puente (Belo Horizonte: UFMG).

Szlezák, T. A. (2009), Platão e a escritura da Filosofia: Análise de estrutura dos diálogos da juventude e da maturidade à luz de um novo paradigma hermenêutico, tradução de $\mathrm{M}$. Camargo (São Paulo: Loyola).

Szlezák, T. A. (2011) A imagem do dialético nos diálogos tardios de Platão, tradução de W. Fuchs e revisão de M. Perine (São Paulo: Loyola).

Trabattoni, F. (1994), Scrivere nell'anima. Verità, dialettica e persuasione in Platone (Firenze: La Nuova Italia).

Trabattoni, F. (2003), Oralidade e escrita em Platão, tradução de F. Rey Puente e R. Bolzani Filho (São Paulo: Discurso Editorial).

Vlastos, G. (1981), Platonic Studies (Princeton: Princeton University Press).

Yunis, H. (2014), “Introduction” en Platão, Phaedrus, editado por H.Yunis (Cambridge: Cambridge University Press, 9-56).

Zuckert, C. (1996), Postmodern Plato: Nietzsche, Heidegger, Gadamer, Strauss, Derrida (Chicago: The University of Chicago Press).

Recibido: 09-01-2020; aceptado: 11-05-2020 